\title{
Checking for 'Checkpoints': Using course design to redefine engagement in Early-warning system learner analytics
}

Authors: Dominic C Henri*, Stuart Nattrass*, Katharine Hubbard, Lesley Morrell, and Graham Scott.

*These authors contributed equally to this work.

\section{Abstract}

In order to maintain pace with rising expectations to provide an 'excellent learning environment', higher education institutions across the world are turning to learner analytics to help allocate resources efficiently. However, the exponential increase of digital learning technologies has resulted in learner analytics sharing the same practical and ethical concerns as 'big data' in the wider context. This study provides an important 'proof-of-concept' that learner analytics is better served by data from theory driven course design, and not more data. We explore the potential of learner analytics combined with course design that incorporates regular, automated, low-stakes assignments to provide 'checkpoints' of student engagement. We show for a cohort of 424 foundation year students that attainment is best predicted by 'checkpoint' submission and not by a host of demographic and behavioural variables that have previously been identified as 'early-warning indicators'. To conclude, we identify how the practice of integrating learner analytics and course design can help us better align our practice with ethical use of data guidelines for learner analytics and the recommendations from the literature.

\section{Introduction}

There has been an international trend of rising expectations for Higher Education institutions to provide a better learning environment; including responsibility for monitoring and managing student wellbeing (Abualrub \& Stensaker 2018; Sladdin 2018; Naidoo \& Williams 2015). In the UK, this has been most evident in changing mission from the sector-focused Higher Education Funding Council for England to the students-as-consumers focus of the Office for Students. In order to meet these expectations while maximising resource allocation efficiency, universities are turning to 'learner analytics', defined as "the measurement, collection, analysis and reporting of data about learners and their contexts, for purposes of understanding and optimizing learning and the environments in which it occurs" (Siemens 2012). Increasing uptake of technology-enhanced learning has meant that 'learner analytics' exercises have an 
increasingly diverse range of sources to extract information on students towards enhancing their learning environment (Kay et al. 2012). This exponential increase in data sources means that 'learner analytics' is encountering the same ethical issues encountered with 'big data' in other spheres; see (Kay et al. 2012; Bollier 2010; Zwitter 2014). The sector at large is grappling with some serious conflicts, 'to what extent does the mandate to improve learning environment justify the collection of increasingly divergent and tangential information on student activity?' and 'how do we determine the ownership, effective storage, and sharing of this data?' (Slade \& Prinsloo 2013; Prinsloo \& Slade 2016; Willis et al. 2016).

For many, there is an assumption that universities have a right [or even the moral responsibility] to collect as much data as possible on the demographics and behaviours of their students, as it maximises the potential to provide support whenever and however it is needed (Siemens 2012; Sciater et al. 2016). However, this position potentially abuses the power relationship between student and institution (Lawson et al. 2016; Prinsloo \& Slade 2016). There are also growing concerns on the diminishing returns and increased legal responsibilities for use and storage associated with spiralling 'data voyeurism'; for example, how small an improvement in learning environment justifies the storage of student location when logged onto the institution network (Pardo \& Siemens 2014)? The concerns expand when considering the wide-spread use of externally-controlled software and systems, such that records are divergent in location, ownership and accessibility (Ferguson 2016; Abualrub \& Stensaker 2018). In the UK, the JISC 'code of practice for learning analytics' states that "[data collection should be] kept to the minimum necessary to deliver the purposes of the analytics reliably" (JISC n.d.). However, the "minimum necessary' is a difficult concept to define and while good best principles are available for learner analytics (Slade \& Prinsloo 2013), empirical evidence to support actioning the principles is sparse (Willis et al. 2016).

A particularly common use of 'learner analytics' is as early-warning systems to promote student retention, student data is fed into sorting algorithms to highlight students in need of support in attempts to focus limited professional services resources (Lawson et al. 2016; Macfadyen \& Dawson 2010; Slade \& Prinsloo 2013). This use of learner analytics is particularly susceptible to two larger issues that stem from the wider 'big data' phenomenon: 'dishonest signals' [a term borrowed from evolutionary signaling theory to describe inaccurate cues] and 'stereotyping'. Certain logic holds that 'more data' is equal to greater resolution to pin-point student support, but in actuality more data can increase the proportion of 'dishonest signals' and mean more confounding variables or false positives (Bollier 2010; Kruse \& Pongsajapan 2012). A common example here is the use of lecture attendance as a measure of student 
engagement, whereby low engagement students are assumed to be at greater risk of non-completion. However, this may be an unreliable indicator for some students; for example, some students may be highly engaged but are unable to attend on-campus taught sessions due to health issues, caring responsibilities or paid employment. While lecture attendance is usually assumed to be a core measurement of course engagement, it does not account for the diversity of modes in which university students learn; i.e. some students effectively use lecture-capture, study-buddies, and core texts instead of attending all of their lectures (Axelson \& Flick 2010; Henrie et al. 2015). Lecture attendance is difficult to collect for a large student body, introduces uncertainties (such as what threshold to set before engaging with support), and presents many opportunities to game the system (such as attending a lecture but not paying any attention); by these measures lecture attendance based early-warning systems do not fit well with the JISC code of practice (JISC n.d.).

In order to provide a stronger evidence-based analytics users are turning to 'data mining': the large-scale use of big data to statistically indicate early-warning characteristics. This comes with a new set of problems in that it reduces individuals down to the sum of their demographic characteristics and behaviours, with the potential to promote bias and stereotyping (Slade \& Prinsloo 2013; Lawson et al. 2016). There is a large body of research looking at pre-registration demographics as indicators of achievement and retention (with a view to providing support for people who fall into certains groups based on demographic information such as age, ethnicity, soceioeconomic status, and disability) (Richardson \& Woodley 2003; Richardson 2008; Connor \& Others 1996). But making decisions based on the 'group' to which a person 'belongs' is a very definition of stereotyping and can easily result in behaviours that exacerbate the problem (Lawson et al. 2016). In the UK, a specific case study of this can be seen with the analytics studies showing that students who completed Business and Technology Education Council post-16 qualifications (BTECs) on average have lower attainment at university than students with equivalent Advanced Level (A-levels) qualifications (Holford 2017; Peake 2018); where BTECs adopt a practical and vocationally-focused learning approach while A-levels adopt a more traditional academic approach of exam-based assessment. There are two documented responses to the difference in attainment between these two 'groups': do not accept students who have BTEC qualifications (Savage 2018), or roll-out blanket support for those students (Holford 2017). Both of these solutions promote stereotyping by reducing individuals to their labels, where giving support to a student because they are part of a certain group can reinforce the negative impacts of being part of that group (Scholes 2016). A core aspect of research in learner analytics must be the identification of underlying processes that explain outcomes, and not conflating traits with risks. 
A possible method to ensure that data are 'honest', immediate, and minimal is to base analytics inputs on education theory. Decades of research on the student perspective of Higher Education shows that their engagement revolves around assessment (Lizzio \& Wilson 2013); a perspective first articulated in the concept of the 'Hidden Curriculum' (Snyder 1970).

"I just don't bother doing the homework now. I approach the courses so I can get an ' $A$ ' in the easiest manner, and it's amazing how little work you have to do if you really don't like the course." (Snyder 1970), ibid, p50)

As educators, whether we mean to or not, we fundamentally measure student engagement with the course assessment; everything else is tangential, if a student attends every lecture and reads every book, they fail if they do not submit assignments (Gibbs \& Simpson 2004). By first grounding our ideas in pedagogic theory, we can identify assessment submission as an 'honest indicator' of engagement, one that is simple to collect, does not require additional consent, and focuses on behaviour not demographics. In order to effectively utilise assessment submission as an early-warning indicator, we must design our course such that they include regular (i.e. weekly or less) 'checkpoints' (Lockyer et al. 2013). A growing body of academics believe the answer to ethically sound learner analytics lies not in more data, but in better course design (Lockyer et al. 2013; Scholes 2016). The use of regular, automated, low-stakes quizzes has been shown to improve student attainment (Voelkel 2013), but it also provides a significant opportunity to create an effective student engagement monitoring system that fits very strongly with the UK code of practice for ethical learner analytics.

In this study we use data from a skills development module for foundation year science students at a UK university to explore the validity of the idea that effective course design can help overcome two of the largest issues in learner analytics. We predict that student submission of weekly assignments in the first half of a semester will be the strongest predictor of student attainment in the second half; even in models that include previously confirmed but tangential demographic and behavioural indicators.

\section{Methods}

\section{Student Data}

We collated behavioural data on all students on the skills module in the academic year 2016/17, a total of 424 individuals. For each of these, we gathered the following information from the first half of the semester, looking at the first 6 weeks of teaching: 
- Total submissions. The total number of assignments (out of seven) from the first half of the module that a student submitted.

- Total attendance. The total number of lectures and workshops attended by the student in the first 6 weeks of teaching.

We also collected data based on knowledge of the student prior to the beginning of semester, including demographic data:

- Gender (male or female only, non-binary designations were not available). Previous work in the UK and abroad has indicated that male students will underperform their female counterparts (Richardson \& Woodley 2003; Lawrence et al. 2006; Kaba 2005; Chee et al. 2005).

- Age at entry: Students aged 21 or over at course registration are given mature student status. Mature students are likely to have more external commitments than younger students and struggle to transition to higher education (Richardson 1995; Wardley et al. 2013) which may make engaging with the university more difficult, yet may also enter university with highly developed non-disciplinary skills (Schofield \& Dismore 2010).

- Nationality of the student, and location of the student's self reported domicile. This allows us to look at effects based on whether the student is local to the university (where the domicile is reported as within Hull or the East Riding), a home but non-local student, or an international student as independent, binary effects. International students may underperform relative to UK students (e.g. (lannelli \& Huang 2014)), while local students are more likely to attend university while still living at home, creating additional commitments beyond study, earmarking these categories as potentially impactful.

- Participation of local areas (POLAR3) quintile. This is a UK wide measure considering the percentage of young people from an area that enter higher education, and is widely used as a measure of participation. Here, POLAR considered in two different ways. first, we use the numeric value of the reported quintile, with higher values representing students from areas with higher participation rates. Secondly, we simultaneously include a binary measure of whether the student falls into the lowest quintile or not. Students within this category are much more likely to need external funding such as part time work to meet the costs of going to university, which correlates with lower performance in UK higher education (Callender 2008). 
- UCAS tariff. This was used as a proxy for prior academic achievement. Mean tariff was 160.8 points, with standard deviation of 111.1.

- The type of institution the student is entering the university from, and the type of qualifications they enter with.

- Whether the student entered the university through the clearing system or not

- The department of study within the university that the student registered within

Table 1: A breakdown of student information known at course registration. Percentages are rounded to the nearest whole percent, and therefore may not add to 100 within a category.

\begin{tabular}{|c|c|c|}
\hline Category & Categorisation & $\begin{array}{l}\text { Number of students } \\
\text { (Percentage) }\end{array}$ \\
\hline \multirow[t]{2}{*}{ Gender } & Male & $286(67 \%)$ \\
\hline & Female & $139(33 \%)$ \\
\hline \multirow[t]{2}{*}{ Mature Student Status } & No & $302(71 \%)$ \\
\hline & Yes & $123(29 \%)$ \\
\hline \multirow[t]{3}{*}{ Local/Home/International } & Local & $117(28 \%)$ \\
\hline & Home non-local & $285(67 \%)$ \\
\hline & International & $23(5 \%)$ \\
\hline \multirow[t]{2}{*}{ Clearing } & Yes & $93(22 \%)$ \\
\hline & No & 332 (78\%) \\
\hline \multirow[t]{6}{*}{ POLAR3 quintile } & 1 & 99 (23\%) \\
\hline & 2 & $70(16 \%)$ \\
\hline & 3 & $72(17 \%)$ \\
\hline & 4 & 79 (19\%) \\
\hline & 5 & $73(17 \%)$ \\
\hline & Unknown & $33(8 \%)$ \\
\hline Type of Qualification & A Levels & $238(56 \%)$ \\
\hline
\end{tabular}




\begin{tabular}{|c|c|c|}
\hline & A Levels \& BTECs & $36(8 \%)$ \\
\hline & BTECs & $51(12 \%)$ \\
\hline & International Baccalaureate & $3(1 \%)$ \\
\hline & None/Other & $97(23 \%)$ \\
\hline \multirow[t]{9}{*}{ Type of Institution } & Academy & $92(22 \%)$ \\
\hline & Free School & $2(<1 \%)$ \\
\hline & $\mathrm{FE} /$ 6th form college & $189(44 \%)$ \\
\hline & HEI & $11(3 \%)$ \\
\hline & Independent school & $14(3 \%)$ \\
\hline & LA maintained school & $53(12 \%)$ \\
\hline & Non UK provider & $3(1 \%)$ \\
\hline & State School & $34(8 \%)$ \\
\hline & Other/Unknown & $27(6 \%)$ \\
\hline \multirow[t]{8}{*}{ Department of Study } & Biology & $98(23 \%)$ \\
\hline & Chemistry & $32(8 \%)$ \\
\hline & Computer Science & $45(11 \%)$ \\
\hline & Engineering & $93(22 \%)$ \\
\hline & Geography/Geology & $34(8 \%)$ \\
\hline & Maths/Physics & $34(8 \%)$ \\
\hline & Psychology & $46(11 \%)$ \\
\hline & Sports Science & $43(10 \%)$ \\
\hline
\end{tabular}

\section{Modeling}

We use the collated data to predict student attainment over the second half of the skills module (weeks 8-11) in two ways. Firstly, did the student pass this part of the module (i.e. get a score of $40 \%$ or higher)? Second, did the student achieve a score of $60 \%$ or higher $(60 \%$ is the threshold for a 2.1 grade, widely 
accepted as a "good" degree in the UK)? Assessed assignments over this time-frame constitute $60 \%$ of the overall module mark. These assignments comprise of four short weekly tests performed within the Virtual Learning Environment (VLE), total $20 \%$ of the module mark, and a longer form essay (40\%) of overall module score. Student attainment over these five assignments was normalised to a 0-100 scale prior to models being assessed.

Using the software R.3.5.0 (R Core Team 2019), we created generalised linear models GLMs with a binomial output for each combination of variables to determine the most important predictors of student attainment. The models with the lowest Akaike Information Criterion (AIC) values were deemed to be the best fitting models.

For both pass/fail and "good" score predictors, we restrict ourselves to models that perform close to as well as the best fitting model $(\triangle \mathrm{AIC}=$ modelAIC - bestmodelAIC $<2)$. For this subset of models, we calculate the weighting $\mathrm{w}$ of each individual model $\mathrm{i}$;

$$
w_{i}=\frac{\exp \left(-0.5 \cdot \Delta \mathrm{AIC}_{i}\right)}{\sum_{r=1}^{R} \exp \left(-0.5 \cdot \Delta \mathrm{AIC}_{r}\right)}
$$

where $\mathrm{R}$ is the number of models considered (here, the number of models with $\Delta \mathrm{AIC}<2$ ).

The variable importance for each possible predictor variable is then given as the sum of the weighting for the models the parameter appears in. The more important a predictor variable is, the closer to 1 the variable importance for that predictor should be.

\section{Results}

\section{Passing the module's second half predictors}

The best fitting model for predicting pass/fail for a student includes both behavioural and information available at enrollment,

PassModule $\sim$ Gender + lowestPolarQuintile + Tariff + Submissions.

The largest impact on whether a student passes the module's second half is the number of submitted assignments, as each additional submission improves the probability of passing the module's second half significantly $(\beta=1.85, z=7.47, p<0.001)$. The model also predicts that students from the lowest POLAR quintile are less likely to score $40 \%$ on the module's second half than students in quintiles $2-5(\beta=-1.29$, $z=-2.69, p=0.007)$. However, this effect size is smaller than the effect of missing assignment 
submissions. The gender and tariff terms improve model fit but are non-significant (gender_male $\beta$ $=-0.89, z=z=-1.48, p=0.14$, tariff $\beta=0.0036, z=1.70, p=0.090)$.

There are 15 pass/fail models with $\triangle A I C<2$. Within these models, both lowest POLAR quintile and number of submissions appear in all 15 models, giving them a variable importance of 1 . They are the only two predictors that have variable importance of over 0.9 (see Table 2).

Table 2: Variable importance for models predicting pass/fail on the second half of the module, based on the models with $\triangle \mathrm{AIC}<2$. Predictor variables with importance greater than 0.9 are highlighted.

\begin{tabular}{|l|c|}
\hline Predictor variable & Variable Importance \\
\hline Submissions & 1 \\
\hline Lowest POLAR quintile & $\mathbf{1}$ \\
\hline UCAS Tariff & 0.87 \\
\hline Gender & 0.669 \\
\hline Mature Student Status & 0.33 \\
\hline Entry via clearing & 0.245 \\
\hline Department of study & 0.123 \\
\hline International student & 0.047 \\
\hline Attendance & 0.043 \\
\hline Local student & 0.043 \\
\hline Nationality & 0 \\
\hline POLAR quintile & 0 \\
\hline Type of previous qualifications & 0 \\
\hline Type of prior institution & 0 \\
\hline
\end{tabular}

Figure 1 shows the relationship between passing the module's second half and assessment task submission. No students who submitted fewer than four of the seven assessments went on the pass the 
module's second half. This is particularly pronounced for students in POLAR quintile 1, where no students with fewer than six submissions in the first six weeks of university passed. However, it is important to note that this conclusion is based on small sample sizes, as only a total of 34 (10 of whom were in POLAR quintile 1) submitted fewer than six assessment tasks.

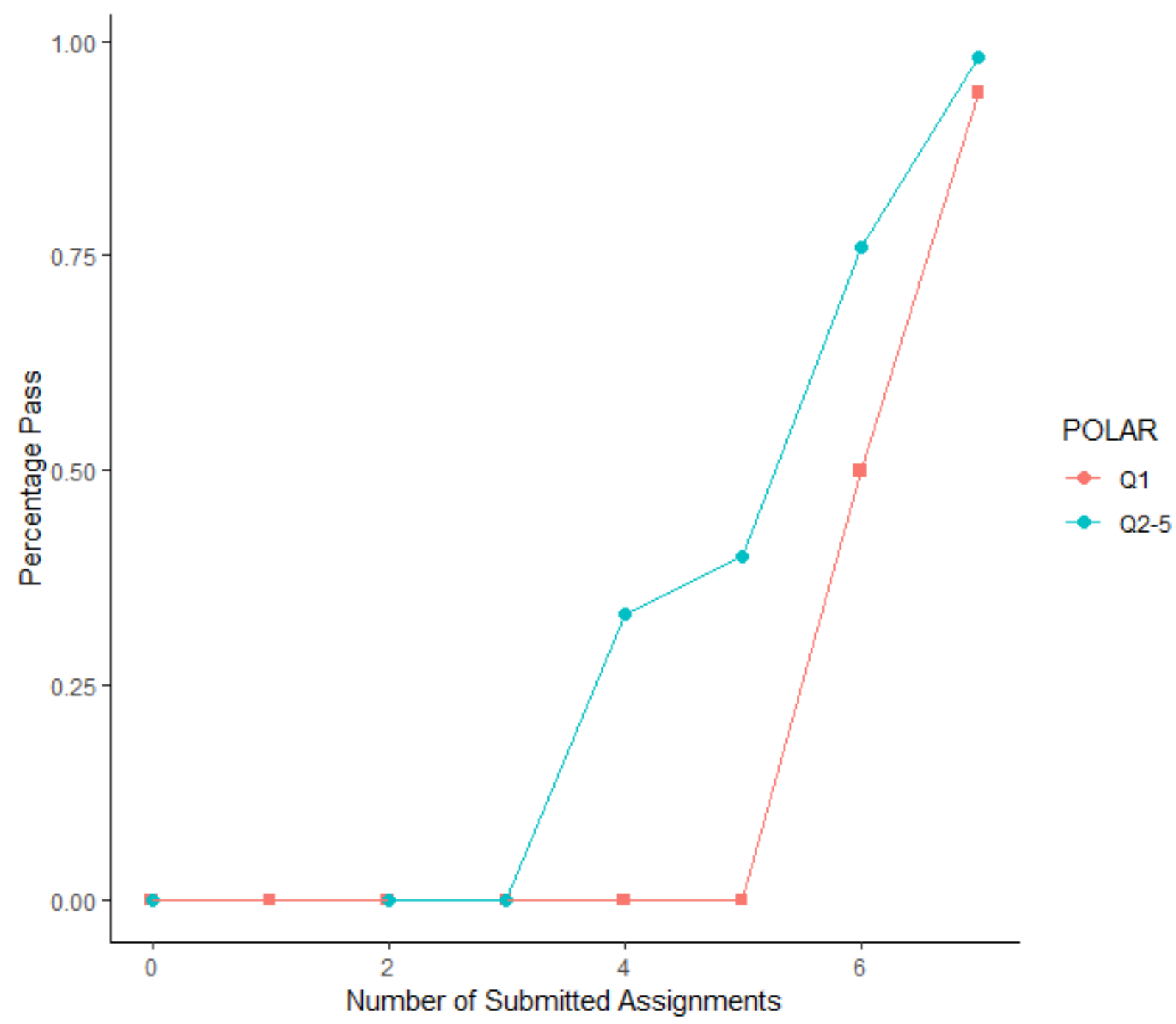

Figure 1: Pass rate of students by number of early submissions. The red line with square points shows students from POLAR quintile 1, while blue, round points show students from quintiles 2-5.

\section{Achieving a "good" score predictors}

The best fitting model predicting whether a student scores $60 \%$ or higher on the second half of the module is given by 
GoodScoreModule $\sim$ international + lowestPolarQuintile + PriorQualifications + Attends + Submissi

Submissions of early assignments remain very strong predictors of performance in the second half of this module $(\beta=1.92, z=5.47, p<0.001)$, while students from the lowest POLAR quintile are still less likely to succeed on the module's second half $(\beta=-0.97, z=-2.43, p=0.015)$. However, while attendance does not impact pass rate, the number of classes attended in the first 6 weeks of the module are a significant predictor of students getting a "good" score $(\beta=0.23, z=2.84, p=0.005)$, and while international students pass at the same rate, they are much less likely than their UK based peers to score $60 \%$ on this module's second half $(\beta=-2.69, z=-5.19, p<0.001)$. Further, students with BTEC qualifications are less likely to score $60 \%$ on the latter half of the module than students with A-levels or other qualifications ( $\beta$ $=-7.90, z=-4.00, p<0.001)$.

There are fewer models with $\Delta \mathrm{AIC}<2$ when looking at good scores than pass fail, with 7 models meeting this threshold. In these seven models, each of the five terms in the best fitting model appears in all seven models, giving variable importance values of 1 for each of them. No other variable considered has a variable importance greater than 0.5 (see Table 3).

Table 3: Variable importance for models predicting high scores on the second half of the module, based on the models with $\triangle \mathrm{AIC}<2$. Predictor variables with importance greater than 0.9 are highlighted.

\begin{tabular}{|l|l|}
\hline Predictor variable & Variable Importance \\
\hline Submissions & 1 \\
\hline International student & 1 \\
\hline Type of previous qualifications & 1 \\
\hline Attendance & 1 \\
\hline Lowest POLAR quintile & 1 \\
\hline Local student & 0.292 \\
\hline Mature Student Status & 0.259 \\
\hline Gender & 0.112 \\
\hline UCAS Tariff & 0.105 \\
\hline Entry via clearing & 0.097 \\
\hline Department of study & 0 \\
\hline
\end{tabular}




\begin{tabular}{|l|l|}
\hline Nationality & 0 \\
\hline POLAR quintile & 0 \\
\hline Type of prior institution & 0 \\
\hline
\end{tabular}

\section{Discussion}

\section{The Value of Checkpoints}

Analysis of student performance on a foundation year module within a UK science faculty supports previous research in concluding that course design can support higher quality learning analytics, by providing focused data points on students that can support stronger predictive models (Lockyear 2013). Regular assignments throughout the module can be 'checkpoints' for student engagement, and are the single largest predictor of future student performance - the more assignments missed by a student, the poorer future performance we saw. Further, no student who submitted fewer than 4 assignments in the first six weeks of the module went on to score a pass grade for the second half of the module, indicating that missed submissions are a key predictor of future achievement.

However, submission of all 7 assignments in the first six weeks did not guarantee student success. Indeed, demographic signifiers did impact performance in our models, as at least one demographic signifier was important in each of the models considered (Table 2, Table 3). While these demographic factors are currently signifiers of student attainment, it is important to understand why these predictors are impacting students. For example, students from areas with the lowest participation in higher education (POLAR) are less likely to pass the module considered here than students from higher participation backgrounds, but what about this factor is impacting the student? This echoes prior research suggest that socioeconomic background has significant impacts on the student attainment in higher education (Thiele et al. 2016). However, not all students from a demographic group are identical, and several students excel in higher education even when current data mining approaches to learning analytics flag them as "at risk". Of the 83 POLAR quintile 1 students in our sample who submitted all 7 assignments, 78 (94\%) passed the latter half of the module. This use of data mining approaches to determine demographic characteristics as pre-warning indicators of attainment (Kerby 2015), can contravene many of the best practices in learner analytics (Willis et al. 2016; Prinsloo \& Slade 2016; Lawson et al. 2016). It is integral that staff/students are not presented with a narrative that the student 
is at risk because of the group that they are a part of, as this moves the agency away from the intrinsic toward the extrinsic (with corresponding changes in motivation and self-efficacy) (Wang et al. 2018; Basile \& Lopez 2015; Scholes 2016).

We note that demographics based analytics can provide important information to develop inclusive interventions. However, big data must be paired with rich qualitative data to help us find underlying causative drivers of low retention and/or attainment (Scholes 2016; Kerby 2015; Xu \& Webber 2018). Taking a key example from the impact of pre-degree qualifications in the UK, qualitative research shows us that different assessment approaches in post-16 education impact on student understanding of the 'hidden curriculum' (Hatt \& Baxter 2003). It is commonly the case that 'inclusive education' interventions benefit everyone, irrespective of whether they are part of the target group (Thomas 2012). For example, the adopting of more equitable assessment practices can benefit the attainment of all students irrespective of socioeconomic background or prior educational pathway (Nattrass et al. 2019).

\section{The benefits of basing inputs on educational theory}

The use of individualised, behavioural data for students not only reduces the risk of stereotyping based on demographic factors, it also improves the predictions of our learning analytics framework. Here, we show that without the existence of 'checkpoint' assignments, predictions for both progression/retention (passing the module) and high attainment would be worse than when those assignments are included. we therefore highlight the value of course design for better learner analytics (Smallhorn 2017; Lockyer et al. 2013; Roberts et al. 2017).

By using pedagogy and educational theory to guide course design that can improve learning analytics, we can improve the ethics and efficiency of our learning analytics platform in multiple ways:

1. Minimal data collection - the use of course data that is used and immediately discarded can minimise the storage of data, reducing the ethical concerns of stored data (Ferguson 2016) and minimising the potential for the abuse of university power structures (we use clear rationale to explain what data needs collecting when asking for consent) (Lawson et al. 2016; Slade \& Prinsloo 2013; Pardo \& Siemens 2014).

2. Greater focus on the individual and not the context - thus reducing stereotyping (Scholes 2016). While some demographic contexts do appear as significant indicators within our models, the most important predictors for both passing the module and high attainment are behavioural signals that allow us to prioritise the individual over those contexts. 
3. Transparent use and collection of data - course data has minimal issues with ownership (Lawson et al. 2016).

4. Direct measure of engagement - the use of a direct measure of engagement such as assignment submission minimises the likelihood of 'faulty-evidence' (Kruse \& Pongsajapan 2012), whereby students 'cheat' the system (for example, asking a friend to mark them as attending a class, or even being present but inattentive).

5. Simple - no need for additional training or large-scale management, as this type of data is already handled routinely (Lockyer et al. 2013)

6. Immediate - identifies need for support as it happens, but does not persist in records once issues have been resolved (Mayer-Schonberger 2009)

We do not believe the 'case study' nature of this report limits the wider validity of the recommendations; theoretically and empirically, assessment is the point at which student engagement with the course is measured (Gibbs \& Simpson 2004). The primary limitation with an 'assessments as checkpoints' approach is that for many courses this would only provide two points of engagement (the winter and summer exam periods), which is insufficient for the purposes of student monitoring. Our approach, therefore, requires engagement across departments by all stakeholders and possibly individualised processes for different courses; which is a major barrier for large institutions. Having a single 'canary in the mine' module may be sufficient (multiple weekly tests is likely to be overwhelming); however, we do assume that attainment on this module is indicative of overall course attainment. This may not be appropriate for all courses and some may wish to incorporate regular checkpoints for different sources of difficulty (e.g. some students may have particular difficulties with numerical aspects of the course while others with practical-based).

An area that this study does not elucidate is how we engage students with information collected on them. There are some common sense approaches to avoid, such as 'you are at high risk of failure', and 'people like you are at high risk of failure' narratives (Lawson et al. 2016). There is a great need for more research on how to effectively engage students highlighted by learner analytics systems as many questions remain unresolved: who is responsible, how should the student be contacted, how should it be escalated, what kind of support should be provided, and when should the information be shared with emergency contacts? 


\section{Conclusions}

There are ethical concerns with institutions continuing to collect so much information on students. While making students aware of data being collected and how it will be used is an important aspect of the future of learner analytics, there is a significant body of literature questioning whether students are 'ethically' able to provide informed consent (Willis et al. 2016; Prinsloo \& Slade 2016; Prinsloo \& Slade 2017). The burden of deciding the definition of 'minimum necessary' must fall on the institution, which means that inputs into learner analytics should be considered, supported by theory, and most importantly stem from course design. This report provides an important proof-of-concept in that integrated course design (and not more advanced analytics) is an important step towards meeting the ethical guidelines for the use of learner analytics (JISC n.d.). Future studies should elucidate best practice for engaging students with the results and establishing clearer guidelines on 'minimum necessary' justifications of data collection, storage, and inclusion in learner analytics (Lawson et al. 2016).

\section{References}

Abualrub, I. \& Stensaker, B., 2018. How are universities responding to demands for an improved learning environment? Journal of Further and Higher Education, 42(5), pp.721-732.

Axelson, R.D. \& Flick, A., 2010. Defining Student Engagement. Change: The Magazine of Higher Learning, 43(1), pp.38-43.

Basile, V. \& Lopez, E., 2015. And Still I See No Changes: Enduring Views of Students of Color in Science and Mathematics Education Policy Reports. Science education, 99(3), pp.519-548.

Bollier, D., 2010. The Promise and Peril of Big Data, The Aspen Institute. Available at: https://assets.aspeninstitute.org/content/uploads/files/content/docs/pubs/The_Promise_and_Peril _of_Big_Data.pdf.

Callender, C., 2008. The impact of term-time employment on higher education students' academic attainment and achievement. Journal of Education Policy, 23(4), pp.359-377.

Chee, K.H., Pino, N.W. \& Smith, W.L., 2005. Gender differences in the academic ethic and academic achievement. College student journal, 39(3), pp.604-619.

Connor, H. \& Others, A., 1996. Ethnic Minority Graduates: Differences by Degrees. Report 309, BEBC Distribution, 15 Albion Close, Parkstone, Poole BH12 3LL, England, United Kingdom.

Ferguson, R., 2016. Guest Editorial: Ethics and Privacy in Learning Analytics. Journal of Learning Analytics, 3(1), pp.5-15.

Gibbs, G. \& Simpson, C., 2004. Does your assessment support your students' learning. Journal of 
Teaching and learning in Higher Education, 1(1), pp.1-30.

Hatt, S. \& Baxter, A., 2003. From FE to HE: Studies in Transition: A comparison of students entering higher education with academic and vocational qualifications. Widening Participation and Lifelong Learning, 5(2), pp.18-29.

Henrie, C.R. et al., 2015. Exploring intensive longitudinal measures of student engagement in blended learning. The International Review of Research in Open and Distributed Learning, 16(3). Available at: http://www.irrodl.org/index.php/irrodl/article/view/2015.

Holford, A., 2017. Students with BTECs do worse at university - here's how we close the gap. The Guardian. Available at:

http://www.theguardian.com/higher-education-network/2017/nov/29/students-with-btecs-do-wor se-at-university-heres-how-we-close-the-gap [Accessed July 5, 2019].

lannelli, C. \& Huang, J., 2014. Trends in participation and attainment of Chinese students in UK higher education. Studies in Higher Education, 39(5), pp.805-822.

JISC, Code of practice for learning analytics. JISC.ac.uk. Available at: https://www.jisc.ac.uk/guides/code-of-practice-for-learning-analytics [Accessed July 3, 2019].

Kaba, A.J., 2005. Progress of African Americans in higher education attainment: The widening gender gap and its current and future implications. Education policy analysis archives, 13(0), p.25.

Kay, D., Korn, N. \& Oppenheim, C., 2012. Legal, Risk and Ethical Aspects of Analytics in Higher Education, JISC \& CETIS. Available at:

https://digital.fundacionceibal.edu.uy/jspui/bitstream/123456789/282/1/Legal-Risk-and-Ethical-As pects-of-Analytics-in-Higher-Education-Vol1-No6.pdf.

Kerby, M.B., 2015. Toward a New Predictive Model of Student Retention in Higher Education: An Application of Classical Sociological Theory. Journal of college student retention: research, theory \& practice, 17(2), pp.138-161.

Kruse, A. \& Pongsajapan, R., 2012. Student-centered learning analytics. CNDLS Thought Papers, pp.1-9.

Lawrence, J., Ashford, K. \& Dent, P., 2006. Gender differences in coping strategies of undergraduate students and their impact on self-esteem and attainment. Active Learning in Higher Education, 7(3), pp.273-281.

Lawson, C. et al., 2016. Identification of "at risk" students using learning analytics: the ethical dilemmas of intervention strategies in a higher education institution. Educational technology research and development: ETR \& D, 64(5), pp.957-968.

Lizzio, A. \& Wilson, K., 2013. First-year students' appraisal of assessment tasks: implications for efficacy, engagement and performance. Assessment \& Evaluation in Higher Education, 38(4), pp.389-406.

Lockyer, L., Heathcote, E. \& Dawson, S., 2013. Informing Pedagogical Action: Aligning Learning Analytics With Learning Design. The American behavioral scientist, 57(10), pp.1439-1459.

Macfadyen, L.P. \& Dawson, S., 2010. Mining LMS data to develop an "early warning system" for 
educators: A proof of concept. Computers \& education, 54(2), pp.588-599.

Mayer-Schonberger, V., 2009. Delete: The Virtue of Forgetting in the Digital Age, Princeton, NJ, USA: Princeton University Press.

Naidoo, R. \& Williams, J., 2015. The neoliberal regime in English higher education: charters, consumers and the erosion of the public good. Critical Studies in Education, 56(2), pp.208-223.

Nattrass, S. et al., 2019. Can Changes To Assessment Strategy To Improve Student Outcomes Be Equitable? Available at: https://edarxiv.org/qmbe4/.

Pardo, A. \& Siemens, G., 2014. Ethical and privacy principles for learning analytics. British journal of educational technology: journal of the Council for Educational Technology, 45(3), pp.438-450.

Peake, R., 2018. “We are not all equal!” Learning and Teaching, 11(3), pp.80-96.

Prinsloo, P. \& Slade, S., 2017. Chapter 4 - Society for Learning Analytics Research (SoLAR). In Charles Lang George Siemens Alyssa Wise Dragan Gašević, ed. Society for Learning Analytics Research (SoLAR). Society for Learning Analytics Research, pp. 49-57.

Prinsloo, P. \& Slade, S., 2016. Student Vulnerability, Agency, and Learning Analytics: An Exploration. Journal of Learning Analytics, 3(1), pp.159-182.

R Core Team, 2019. R: A language and environment for statistical computing. Available at: http://www.R-project.org/.

Richardson, J.T.E., 1995. Mature students in higher education: II. An investigation of approaches to studying and academic performance. Studies in Higher Education, 20(1), pp.5-17.

Richardson, J.T.E., 2008. The attainment of ethnic minority students in UK higher education. Studies in Higher Education, 33(1), pp.33-48.

Richardson, J.T.E. \& Woodley, A., 2003. Another Look at the Role of Age, Gender and Subject as Predictors of Academic Attainment in Higher Education. Studies in Higher Education, 28(4), pp.475-493.

Roberts, L.D., Chang, V. \& Gibson, D., 2017. Ethical Considerations in Adopting a University- and System-Wide Approach to Data and Learning Analytics. In B. Kei Daniel, ed. Big Data and Learning Analytics in Higher Education: Current Theory and Practice. Cham: Springer International Publishing, pp. 89-108.

Savage, M., 2018. Top universities accused of BTec snobbery. The Guardian. Available at: http://www.theguardian.com/education/2018/jan/27/universities-btec [Accessed July 5, 2019].

Schofield, C. \& Dismore, H., 2010. Predictors of retention and achievement of higher education students within a further education context. Journal of Further and Higher Education, 34(2), pp.207-221.

Scholes, V., 2016. The ethics of using learning analytics to categorize students on risk. Educational technology research and development: ETR \& D, 64(5), pp.939-955.

Sciater, N., Peasgood, A. \& Mullan, J., 2016. Learning Analytics in Higher Education: A review of UK and 
international practice, JISC. Available at:

https://www.jisc.ac.uk/sites/default/files/learning-analytics-in-he-v3.pdf.

Siemens, G., 2012. Learning Analytics: Envisioning a Research Discipline and a Domain of Practice. In Proceedings of the 2Nd International Conference on Learning Analytics and Knowledge. LAK ' 12. New York, NY, USA: ACM, pp. 4-8.

Sladdin, J., 2018. Duty to care for student mental health has legal implications for universities. Pinsent Masons. Available at: https://www.pinsentmasons.com/out-law/analysis/duty-to-care-student-mental-health-legal-implic ations-universities [Accessed July 9, 2019].

Slade, S. \& Prinsloo, P., 2013. Learning Analytics: Ethical Issues and Dilemmas. The American behavioral scientist, 57(10), pp.1510-1529.

Smallhorn, M., 2017. The flipped classroom: A learning model to increase student engagement not academic achievement. Success in Soccer, 8(2), p.43.

Snyder, B.R., 1970. The Hidden Curriculum, Cambridge: Mass., Mit Press.

Thiele, T. et al., 2016. Predicting students' academic performance based on school and socio-demographic characteristics. Studies in Higher Education, 41(8), pp.1424-1446.

Thomas, L., 2012. Building student engagement and belonging in Higher Education at a time of change. Paul Hamlyn Foundation, 100. Available at: https://www.heacademy.ac.uk/sites/default/files/resources/What_works_final_report.pdf.

Voelkel, S., 2013. Combining the formative with the summative: the development of a twostage online test to encourage engagement and provide personal feedback in large classes. Research in Learning Technology, 21. Available at: https://journal.alt.ac.uk/index.php/rlt/article/view/1349 [Accessed July 8,2019$]$.

Wang, H. et al., 2018. A Longitudinal Study of the Impact of Attending an Inclusive STEM High School: The Case for Using Two Comparison Groups. Society for Research on Educational Effectiveness. Available at: http://files.eric.ed.gov/fulltext/ED591587.pdf [Accessed May 8, 2019].

Wardley, L.J., Bélanger, C.H. \& Leonard, V.M., 2013. Institutional commitment of traditional and non-traditional-aged students: a potential brand measurement? Journal of Marketing for Higher Education, 23(1), pp.90-112.

Willis, J.E., Slade, S. \& Prinsloo, P., 2016. Ethical oversight of student data in learning analytics: a typology derived from a cross-continental, cross-institutional perspective. Educational technology research and development: ETR \& D, 64(5), pp.881-901.

Xu, Y.J. \& Webber, K.L., 2018. College Student Retention on a Racially Diverse Campus: A Theoretically Guided Reality Check. Journal of college student retention: research, theory \& practice, 20(1), pp.2-28.

Zwitter, A., 2014. Big Data ethics. Big Data \& Society, 1(2), p.2053951714559253. 
